\title{
Enhancing geneticists' perspectives of the public through community engagement
}

\author{
Julianne M. O'Daniel, MS ${ }^{1,4}$, Katie D. Rosanbalm, PhD², Larry Boles, BA ${ }^{3,4}$, Genevieve M. Tindall, BA', \\ Troy M. Livingston, $\mathrm{BS}^{3}$ and Susanne B. Haga, $\mathrm{PhD}^{1}$
}

Purpose: Given the rapid pace of genetic and genomic research and technology development, public engagement on scientific issues may be mutually beneficial to the research community and the general public. The public may benefit from a greater understanding of concepts and new applications, and researchers can build awareness of public knowledge, perceptions, and potential concerns about genomic research and applications.

Methods: We developed and piloted a public engagement program called Genome Diner to facilitate dialog between genetic/genomic researchers $(n=40)$ and middle school students $(n=76)$ and their parents $(n=83)$ from the local community. Program impact was assessed through pre- and post-Diner surveys for each group.

Results: After participation in Genome Diner, researchers' views were positively affected regarding the (adult) public's level of understanding of genetic concepts, beliefs about relevance of research, and the importance of researcher-community interaction.

Conclusion: Through an interactive discussion with students and parents, researchers gained valuable insight into public perspectives about genome research. The engagement format of the Genome Diner program presents a novel method of fostering trust and relationships between the two groups and to inform both the public and the researchers, whose work may depend on public opinion and participation.

Genet Med 2012:14(2):243-249

Key Words: community; education; engagement; geneticists; genomics; public attitudes

\section{INTRODUCTION}

Since the completion of the sequencing of the human genome, the pace of genetics and genomic research has rapidly escalated, as evidenced by the endless reports of new discoveries. Several studies have reported positive public attitudes about genetic research and genetic testing. ${ }^{1-4}$ Although some studies have reported low levels of public understanding of genetic concepts, ${ }^{3,5,6}$ the general knowledge level may be increasing. ${ }^{6}$ In comparison, little data are available about researchers' views of public understanding and interest in science, particularly genetics and genomic research. Researcher knowledge of the public's level of understanding and views of genomic research and applications can aid in structuring public communications and addressing potential concerns regarding research participation or use of new genomic technologies.

Science communication can be a dynamic two-way exchange of knowledge "between scientists and the lay public in order to achieve a reciprocal understanding." The scientific concepts that scientists wish to communicate, however, may not always align with the interests and unique perspectives of the public. Many "education" events tend to emphasize the organizers' interests rather than engaging a broad audience and being responsive to their interests. ${ }^{8,9}$ Therefore, for such efforts to be successful, one approach scientists can take is to highlight the personal relevance of science for their audience. This may be framed, for example, by ethnic and cultural environments of the individual and community.,10-13 The idea of a singular, static public disregards the diversity of current societies and their different experiential influences and attitudes that can change over time. ${ }^{7-9,12}$

Efforts toward increasing public understanding of science have undergone a recent paradigm shift. Traditional approaches followed a "deficit model" in which suspicions and negative attitudes toward genome technologies were considered to be the product of gaps in factual science knowledge and public awareness. ${ }^{8,9}$ However, the perceived deficit in knowledge may actually lie with the experts in their lack of appreciation for community concerns and personal meaning of research information. ${ }^{8,13}$ New approaches have diverged from this traditional model and moved toward more reciprocal interaction between scientists and members of the community.

One such approach is that of the "science cafe" concept in which scientific experts interact with community members through informal lectures and discussions. This informal

\footnotetext{
${ }^{1}$ Institute for Genome Sciences \& Policy, Duke University, Durham, North Carolina, USA; ${ }^{2}$ Center for Child and Family Policy, Social Sciences Research Institute, Duke University, Durham, North Carolina, USA; ${ }^{3}$ Museum of Life \& Science, Durham, North Carolina, USA; ${ }^{4}$ Present address: Illumina, Inc, San Diego, California, USA (J.M.O.); Walt Disney World Resorts, Lake Buena Vista, Florida, USA (L.B.). Correspondence: Julianne M. O’Daniel (jodaniel@illumina.com)
} 
science education approach has been used by various groups throughout the United States and internationally (see http:// www.sciencecafe.org, and http://www.cafescientifique.org). ${ }^{14}$ An evaluation of science cafés from organizer, speaker, and participant perspectives revealed positive experiences. ${ }^{15}$ However, some perspectives included the critiques that there was less interaction than desired and that attendees had a high level of scientific interest bias such that it may not have been engaging the general public. ${ }^{15}$ Because these are scientist-led events, they also may not be as powerful in educating the scientists themselves as regards to community attitudes, knowledge, and perceptions.

We sought to develop a program in which the scientific expert was a participant alongside attendees rather than a presenter. Thus, to promote mutual awareness and enable informed deliberation of issues related to research and application of genome sciences, we developed and piloted an interactive program called Genome Diner. The program concept was loosely modeled after the European discussion card game DeMocs, developed by the New Economics Foundation, ${ }^{16}$ which was shown to be effective in stimulating interactive discussion and idea exchange about topics in science and technology ${ }^{17}$ Our program aimed to bridge formal (public school) and informal (community-based science museum) aspects of science learning within the experiential context of family and participatory learning. The resulting Genome Diner program engages middle school students and their parents in a thoughtful dialog about genome science and related social issues alongside university researchers. In this study, we describe the development and final program elements of the Genome Diner program and the results of the 2-year pilot program with respect to assessment of its impact on the researcher participants. Assessment results for student and parent/guardian participants will be presented in a separate work.

\section{METHODS}

\section{Program development}

In a partnership between the Duke Institute for Genome Sciences \& Policy and the Museum of Life and Science in Durham, North Carolina, we developed a three-part interactive discussion game based on a diner theme. The Genome Diner program was arranged as a "menu": Appetizers (warm-up questions), Main Course (discussion topics), and Dessert (brief summary of discussion from each table). The program materials were developed by the study team based on a review of existing public engagement programs $\mathrm{s}^{16,18,19}$ and team members' collective experiences in communication, as well as published public perceptions of genetics. Two current areas of genome research were selected for the program's "Main Course": (i) population-targeted genomic research, in which a study focuses on learning more about genetic variation within a defined population (e.g., by race, sex, nationality, geographic region) and (ii) genomic health/trait association research, in which a study attempts to learn more about genetic markers linked to a particular phenotype (e.g., heart disease, diabetes, hair color, height, musical ability). Both topics were purposely broad based to allow participants to consider a range of studies. For each discussion topic, we developed a card set of background science and related issues and discussion questions. The background science cards included concepts such as the level of genetic similarity between individuals and what "genetic association" means. Background issue cards included topics such as genetic discrimination, health disparities, and genetic testing for various diseases and traits. Finally, discussion question cards served to initiate discussion among participants and researchers about potential benefits and harms of the research, what type of information could be gained from an association study, and interest in participating in a genomic study or learning of a genetic predisposition.

Materials were pretested through a focus group of nine adults recruited from the Durham community. Additional feedback was obtained through consultation with science teachers from the initial pilot middle school. Materials were revised accordingly for general interest, understandability, and appropriateness of content. Final materials are available online at: http:// www.genome.duke.edu/genomediner/.

\section{Participants}

Three groups were recruited for the pilot study: middle school students, their parent/guardian(s), and genetic/genomic researchers. We specifically targeted seventh- and eighth-grade students at two partner middle schools, because both grades were introduced to basic genetic concepts and applications within the past year. Students were eligible to participate if a parent or guardian consented to participate. Proficiency in English was also required because program materials were available only in English. The program was advertised to students and parents through the partner middle schools by means of flyers, science class and schoolwide announcements, parent-teacher e-mails, and posting on the school webpage. In addition, we sent announcements to science teachers at nearby middle schools and the local home-schooling network. Researcher participants were recruited from the faculty and staff of Duke University and Medical Center through flyers and department e-mail announcements. Researchers were eligible to participate if they held a master's degree or higher and were currently performing genetic or genomic research or both. The study was approved by the institutional review board of Duke University and Medical Center.

\section{Researcher workshop}

Researcher participants were required to attend a 1-hour community engagement training workshop developed and led by investigators from the Museum of Life and Science. The purpose of the workshop was to encourage and provide guidance to the researchers in regards to interacting with the public about science. Activities included how to explain your area of research in 30 words or less.

\section{Genome Diner sessions}

Eight sessions were held during 2009 and 2010 at the two partner middle schools. Each session was held from 6 to 8 PM on 
weekday evenings in the school cafeteria, and a catered meal was provided to all participants. On arrival at the Genome Diner session, informed consent was obtained from parents and assent obtained from students. Parent/student dyads or triads were assigned to tables with a facilitator from the Museum of Life and Science and a researcher (tables ranged from 6 to 10 participants total). To maximize participant engagement, the format was purposely designed to be interactive rather than didactic, and the researchers did not lead the discussion but rather were to engage in the activity like a participant who happened to know about genetics/genomics. At the start of the session, all the participants, including the researcher, introduced themselves. The facilitator then guided the participants at the table through several warm-up questions printed on the menu, such as "Does the food you are eating have DNA?" "What is a gene?" and "If you were to draw a genetic scientist, what would they look like?" Public participants were encouraged to ask the researcher clarifying questions if needed and not to rely on them for answers. The facilitator at each table guided participants through the program materials. After a topic was chosen by the table, the themed cards were distributed around the table and read aloud to the table by each participant (public and researcher) following the "menu" sequence: science cards, issue cards, and then discussion question cards. All participants were encouraged to question and discuss any of the cards as they were read aloud, and the facilitator probed for opinions, if needed. The researchers interacted as coparticipants with the community members and were encouraged to engage in open dialog. At any time, researchers could ask public participants what they thought about any of the cards and vice versa. Total time allotted to the discussion averaged 60-75 minutes. At the end of the discussion time, each group was asked to summarize their table's discussion to the other tables. All participants received a voucher for free admission to the Museum of Life and Science.

\section{Survey development}

To assess the impact of program participation, we developed surveys to be administered before and after the Genome Diner program for all three participant groups. Researcher participants were surveyed before and after an introductory workshop to the program and after participation in their Genome Diner session. Data from the pretraining (hereafter referred to as preDiner) and post Genome Diner program (hereafter referred to as post-Diner) surveys are reported here.

Parent/guardian and student participants were surveyed before and after the Genome Diner program (data to be published separately). The surveys for all groups were designed to allow parallel comparisons between the public (parent and student) and researcher groups where possible. For example, the item "The general public thinks that genetic research does not affect them" would read "Genetic research does not affect me" for public participants.

The researcher participant surveys (pre- and post-Diner) comprised the following sections:
Demographics. To gather basic background information, 10 demographics questions were asked, specifically regarding the level/ type of researcher education and fields of study and practice (pre-Diner survey only).

Knowledge estimation. To assess how well researchers understand the public's knowledge level pertaining to genetic concepts, researchers were asked to estimate the proportion of community members who would correctly answer eight true or false questions about genetics (pre- and post-Diner surveys). These items, along with the attitude items described next, were adopted from previous studies to assess public knowledge of and attitudes toward genetics. ${ }^{20,21}$

Attitude estimation. To assess researchers' awareness of public perceptions and attitudes pertaining to genetic research, researchers were asked to rate their level of agreement with 24 statements using a visual analog scale with anchors for strongly disagree (0) and strongly agree (10) (pre- and postDiner surveys). Researchers placed a mark on a line between these anchors to indicate their level of agreement. Attitude items were divided into the following three subscales (answers averaged within subscales after reverse coding where necessary):

1. Understanding and Positive Feelings: this subscale contained eight items that assess researchers' beliefs that the general public understands genetic research and feels good about it. The items in this subscale have acceptable internal consistency (Cronbach's $\alpha=0.73$ ).

2. Trust: this subscale contained nine items that assess researchers' beliefs that the general public trusts researchers and is willing to participate in genetic research (Cronbach's $\alpha=0.73$ ).

3. Worry: this subscale contained seven items that assess researchers' beliefs that the general public is worried about genetic research and the possible implications of genetics findings (Cronbach's $\alpha=0.72$ ).

Researcher attitudes. Four visual analog scale questions assessed researchers' perceived value of engaging the public around topics of genomic research. These items are combined into a single subscale, Importance of Engagement, with a Cronbach's $\alpha$ of 0.63 .

Engagement experience. Five multiple-choice and visual ana$\log$ scale questions assessed researcher experiences with public engagement before participation in the Genome Diner program. These items were used descriptively and to examine differential effectiveness of the Genome Diner based on previous experiences; therefore, they were collected only pre-workshop.

Engagement confidence. Six visual analog scale items assessed researcher confidence and knowledge related to community engagement and community-based participatory research. These items form a subscale with a Cronbach's $\alpha$ of 0.80 . 
Program satisfaction. Program satisfaction was assessed using eight visual analog scale items and 10 open-ended items postworkshop and post-Diner.

\section{Survey analysis}

Forty research participants completed both the pre- and postDiner surveys and were included in analyses. For the visual analog scales, responses were manually measured to the nearest tenth of a centimeter, with a possible range of 0 to 10 . Descriptive statistical analysis was conducted to examine participant demographics, previous engagement experience, and baseline knowledge and attitudes. Change over time, from baseline to later assessments, was assessed using paired $t$ tests for continuous visual analog scale items (e.g., attitudes) and for subscales. To examine predictors of researcher responses and assess differences between community responses as compared with researcher expectations, general linear models with Tukey post hoc comparisons among groups were run.

\section{Participant characteristics}

\section{RESULTS}

A total of 76 students, 83 parents/guardians, and 40 genome science researchers participated in one of eight Genome Diner sessions (including completion of pre- and post-Diner surveys) during a 2-year period. The researcher participants were predominantly white $(75.0 \%)$, representing diverse genetic/ genomic fields of study, including basic, computational, statistical, biomedical, clinical, and social sciences research from several departments and institutes at the Duke University and Medical Center (Table 1). In the second year of the pilot study, we also asked researchers whether they had participated in a community-targeted science activity; $46 \%$ indicated that they had participated in at least one activity within the past 6 months. The majority of student participants were in the seventh grade $(71 \%)$; the remainder were in sixth, eighth, or ninth grade. Fifty-three percent of parent/guardian(s) self-reported as African Americans, $43.4 \%$ were white, and $80.8 \%$ had a bachelor's or graduate degree (thus representing a well-educated subsample of the community). Although socioeconomic characteristics are not reported for the parent/guardian populations of each school, for comparison, data from the city of Durham, North Carolina, reports a population that is $43.6 \%$ white and $42.1 \%$ black/African American and in which $45 \%$ have a bachelor's degree or higher. ${ }^{22}$

Parent/guardian and student participant results will be published separately. Some data are included where relevant, however, to assist in contextualizing researcher data.

\section{Changes in researchers' perspectives}

In the pre- and post-Diner surveys, we asked researcher participants to indicate their perceptions of public knowledge of genetics/genomics and attitudes toward genome research and applications. We identified several significant changes in researcher perceptions about public understanding of genomic research, broadly grouping them into three categories: (i) perceptions
Table 1 Characteristics of researcher participants

\begin{tabular}{|c|c|}
\hline Researcher demographics & Researchers $(n=40)$ \\
\hline Male & $50.0 \%$ \\
\hline \multicolumn{2}{|l|}{ Race } \\
\hline White & $75.0 \%$ \\
\hline African-American & $5.0 \%$ \\
\hline Asian & $10.0 \%$ \\
\hline Multi/other & $10.0 \%$ \\
\hline \multicolumn{2}{|l|}{ Education } \\
\hline Doctorate & $85.0 \%$ \\
\hline Master's & $12.5 \%$ \\
\hline Unknown/not specified & $2.5 \%$ \\
\hline \multicolumn{2}{|l|}{ Years in profession } \\
\hline$<6$ years & $32.5 \%$ \\
\hline $6-10$ years & $22.5 \%$ \\
\hline $11-15$ years & $17.5 \%$ \\
\hline$>15$ years & $27.5 \%$ \\
\hline \multicolumn{2}{|l|}{ Primary research field ${ }^{a}$} \\
\hline Clinical & $37.5 \%$ \\
\hline Basic science & $37.5 \%$ \\
\hline Biomedical & $12.5 \%$ \\
\hline Ethics/policy & $15.0 \%$ \\
\hline $\begin{array}{l}\text { Participation in community engagement } \\
\text { activities in the last } 6 \text { months }{ }^{b}\end{array}$ & $45.8 \%$ \\
\hline
\end{tabular}

of parent participants' knowledge and attitudes; (ii) opinions about the value of public interaction and input; and (iii) perceptions of their own ability to successfully engage members of the community. No researcher characteristics (age, field, education, or years of research experience) were significantly associated with changes over time on these scores.

Perceptions of public knowledge and attitudes. Research participants' perceptions of parent participants' knowledge and attitudes were significantly impacted for 13 of 32 questions asked in the survey (Tables 2 and $\mathbf{3}$ and Supplementary Tables S1-S3 online). For example, pre-Diner, based on the 10-point visual analog scale (0, disagree; 10 , agree), researchers disagreed with the statement "The public has a good understanding of genetics concepts" $(M=3.5)$. Post-Diner, this changed significantly to agreement $(M=5.6 ; t(39)=5.8, P<0.001)$. For specific genetics knowledge questions (true or false), pre-Diner, the researcher participants predicted that, on average, $60.0 \%$ (95\% CI 55.7-64.2) of community adult participants would give correct answers to each of the eight genetics knowledge items. Post-Diner, researchers' predictions significantly increased to $68.9 \%(t(39)=3.6, P<0.001$; Table 2$)$. As compared with actual 
Table 2 Researcher pre-Diner and post-Diner estimates of public (adult) knowledge of genetics

\begin{tabular}{|c|c|c|c|}
\hline & $\begin{array}{l}\text { Pre-Diner, } \\
\text { mean } \\
\text { estimate } \\
\text { (actual) }^{\mathrm{b}}\end{array}$ & $\begin{array}{c}\text { Post-Diner, } \\
\text { mean } \\
\text { estimate }^{\mathrm{a}} \\
\text { (actual) }^{\mathrm{b}}\end{array}$ & $\begin{array}{l}\text { Two-tailed } \\
t \text { statistic }\end{array}$ \\
\hline $\begin{array}{l}\text { 1. You can see a } \\
\text { gene just by } \\
\text { looking at it with } \\
\text { your eyes. }\end{array}$ & $70.6 \%$ (93.9\%) & $72.8 \%(90.0 \%)$ & $t(38)=0.3, \mathrm{~ns}$ \\
\hline $\begin{array}{l}\text { 2. A gene is a piece } \\
\text { of DNA. }\end{array}$ & $56.0 \%(90.4 \%)$ & $73.3 \%(91.3 \%)$ & $\begin{array}{c}t(39)=3.8 \\
P<0.001\end{array}$ \\
\hline $\begin{array}{l}\text { 3. Healthy parents } \\
\text { can have a child } \\
\text { with an inherited } \\
\text { disease. }\end{array}$ & $55.8 \%(97.6 \%)$ & $67.1 \%(96.3 \%)$ & $\begin{array}{c}t(39)=2.8 \\
P<0.01\end{array}$ \\
\hline $\begin{array}{l}\text { 4. If you have a } \\
\text { genetic risk for a } \\
\text { certain disease, } \\
\text { there is no way to } \\
\text { avoid getting that } \\
\text { disease. }\end{array}$ & $49.0 \%(92.7 \%)$ & $64.2 \%(93.8 \%)$ & $\begin{array}{c}t(39)=3.8 \\
P<0.001\end{array}$ \\
\hline $\begin{array}{l}\text { 5. Different body } \\
\text { parts have } \\
\text { different genes. }\end{array}$ & $47.5 \%(64.6 \%)$ & $58.2 \%(60.8 \%)$ & $\begin{array}{l}t(39)=2.5 \\
P<0.05\end{array}$ \\
\hline $\begin{array}{l}\text { 6. A gene is a } \\
\text { disease. }\end{array}$ & $60.8 \%(97.6 \%)$ & $67.5 \%(94.4 \%)$ & $\begin{array}{l}t(39)=2.2 \\
P<0.05\end{array}$ \\
\hline $\begin{array}{l}\text { 7. Most diseases are } \\
\text { completely caused } \\
\text { by things in the } \\
\text { environment. }\end{array}$ & $59.3 \%(74.7 \%)$ & $65.9 \%(75.0 \%)$ & $t(39)=1.6, \mathrm{~ns}$ \\
\hline $\begin{array}{l}\text { 8. A person's DNA } \\
\text { can be used to } \\
\text { specifically identify } \\
\text { them. }\end{array}$ & $80.8 \%(98.8 \%)$ & $82.3 \%(95.0 \%)$ & $t(39)=0.5, \mathrm{~ns}$ \\
\hline Average accuracy & $60.0 \%(88.3 \%)$ & $68.9 \%(86.9 \%)$ & $\begin{array}{c}t(39)=3.6 \\
P<0.001\end{array}$ \\
\hline
\end{tabular}

Table 3 Researcher pre-Diner and post-Diner responses by subscale

\begin{tabular}{lccc} 
Subscale & $\begin{array}{c}\text { Pre-Diner, } \\
\text { mean }\end{array}$ & $\begin{array}{c}\text { Post-Diner, } \\
\text { mean }\end{array}$ & $\begin{array}{c}\text { Two-tailed } \\
\text { t statistic }\end{array}$ \\
\hline $\begin{array}{l}\text { Understanding and } \\
\text { positive feelings }\end{array}$ & 4.8 & 5.7 & $\begin{array}{c}t(39)=5.2, \\
P<0.0001\end{array}$ \\
$\begin{array}{l}\text { Trust } \\
\begin{array}{l}\text { Worry about bad } \\
\text { outcomes }\end{array}\end{array}$ & 5.3 & 5.7 & $t(39)=3.1, P=0.004$ \\
$\begin{array}{l}\text { Importance of } \\
\text { engagement }\end{array}$ & 7.1 & 6.0 & $t(39)=0.2, \mathrm{~ns}$ \\
$\begin{array}{l}\text { Confidence and } \\
\text { knowledge }\end{array}$ & 5.7 & 6.6 & $t(39)=2.5, P=0.02$ \\
\hline
\end{tabular}

ns, not significant.

responses from parents and students, the researcher predictions significantly underestimated public participant knowledge: PreDiner, each item was answered correctly by an average of $88.3 \%$ of parents and $78.5 \%$ of students.
Researcher participants were asked to indicate their level of agreement with several statements regarding public attitudes toward genetic research. In general, researchers' perceptions about public attitudes toward genetic research became more positive after participation in the Genome Diner program. Specifically, scores on the Understanding and Positive Feelings and Trust subscales each improved significantly (Table 3). For example, researchers were initially (pre-Diner) neutral about the statement "The public thinks that genetic research does not affect them," $(M=5.2)$. Post-Diner, responses changed to disagreement $(M=3.9 ; t(39)=3.5, P<0.01)$. In addition, researchers shifted to stronger agreement with the statement "The general public thinks that participating in genetic research is safe" (pre-Diner, $M=5.2$; post-Diner, $M=6.0 ; t(39)=3.1 ; P<0.01$ ). Public participants showed a parallel shift: parent/guardian(s) and students significantly increased their agreement with the statement "I would consider participating in genetic research" (parent/guardian(s): pre-Diner, $M=6.6$; post-Diner, $M=7.3$; $t(78)=2.6 ; P<0.01$, and students: pre-Diner, $M=5.2$; postDiner, $M=6.3 ; t(72)=3.1 ; P<0.003)$.

In contrast, researchers did not change their views about the public level of concern and worry related to genomic research (e.g., "The general public worries about how the findings from genetic research could change their lives," "The general public worries about the consequences of genetic testing for being able to take out insurance"). Correspondingly, parent/guardian(s) and students indicated significantly increased agreement with the parallel statement "I worry about how the findings from genetic research could change my life" (parent/ guardian(s): pre-Diner, $M=4.0$; post-Diner, $M=4.6 ; t(81)=2.0$; $P<0.05$, and students: pre-Diner, $M=4.9$; post-Diner, $M=5.8$, $t(73)=2.6 ; P<0.01)$.

Opinion about value of public interaction. Researchers indicated strong agreement pre- and post-Diner about the importance of public understanding of the implications of genetic research and the positive impact of researcher interaction with the public with respect to the public's views of genetic researchers. On average, across items in this section, agreement on the importance of public engagement was unchanged after their workshop training but increased significantly post-Diner (Table 4). In particular, after participation in the Genome Diner program, researchers had stronger views about the positive impact of researcher-community interaction on both the focus of genetic research and how it is conducted by researchers (pre-Diner, $M=6.0$; post-Diner, $M=7.2 ; t(39)=3.3 ; P<0.01)$.

Ability and willingness to engage the community. After participation in the training workshop, researcher ratings of their confidence and knowledge regarding community engagement increased significantly (Supplementary Table S4 online). PostDiner, confidence ratings improved further. After participation in the Genome Diner program, researcher responses showed increases in knowledge of "strategies for communicating science" $(t(39)=4.1, P<0.001)$, "building relationships with 
diverse people" $(t(39)=3.1, P<0.01)$, and "community-based participatory research" $(t(39)=3.8, P<0.001)$ (Supplementary Table S5 online). There was no significant change in researchers' confidence in their ability to discuss their research with a public audience, although there was a trend toward increasing confidence $(t(39)=1.8, P=0.08)$. Training significantly improved knowledge about community-based participatory research $(t(39)=2.1, P<0.05)$, but actual public engagement through Genome Diner enhanced this knowledge even further. There was also an increase in researchers' likelihood of interacting with the community around a public science activity in the coming year, although it was only marginally statistically significant $(t(39)=2.0, P=0.05)$.

\section{Satisfaction with program}

Researchers indicated significant satisfaction with both the training workshop $(M=7.8)$ and the Genome Diner session $(M=8.5)$. Furthermore, they responded that they felt the experience was beneficial both to the student and parent participants $(M=7.9)$ and to them as genetic researchers $(M=7.6)$. Student and parent participants agreed that it was beneficial (parent, $M=8.6$; student, $M=8.5$ ) and that they enjoyed the opportunity to interact with the researchers (parent, $M=9.0$; student, $M=8.5$ ).

\section{DISCUSSION}

Given the rapid pace of genetic and genomic research and technology development, it is increasingly important for the public to gain an understanding of genetic concepts and associated ethical and policy issues to enable informed deliberation and decision making with respect to participation in genome research studies and use of clinical genome applications. Similarly, it is essential for researchers to be aware of public perceptions and potential concerns about their work because it may promote researcher-participant interactions and development of study-related materials for (prospective) participants. We aimed to develop a program that would mutually promote understanding about current research topics and related ethical and social issues in genetics and genomics. The results presented here demonstrate that participation in an interactive community engagement activity significantly impacted researchers' views.

In particular, we demonstrated that researcher participation in our community engagement program significantly impacted researchers' perceptions of parent participants' knowledge and attitudes, the value of public interaction and input, and researchers' own ability to successfully engage members of the community. Importantly, most of these changes in opinion occurred only after direct interaction with the public as part of the Genome Diner program in which the researchers interacted with the public as fellow participants. In addition to recognizing the importance of an informed public, researchers became more open to the idea that public opinions could contribute to in a positive manner and potentially aid the development of research agendas and study protocols, especially those that involve human subjects. With a better understanding of the public's level of knowledge and their views of genome science research, researchers will be better able to formulate their messages to address public concerns and promote greater understanding, thereby building trust and strengthening relationships between the two groups. Public trust in both the science and the information source is a primary factor in attitudes toward genetic technologies. ${ }^{9,12,23}$ In recognition of this issue, several groups have dedicated education offices or programs such as the National Human Genome Research Institute's Office of Policy, Communications and Education and the UK Department of Health's support of Genetics Knowledge Parks.

Researchers represent a major player in the public's understanding and perception of genome science. However, researchers may be hesitant to participate in public engagement programs because of their negative perceptions of public knowledge and attitudes, low perceived value of participation in such activities, and difficulty in effectively communicating with diverse lay audiences about the significance of their work. Overall, participation in the Genome Diner program (including the workshop and community session) seemed to create an atmosphere that encouraged researchers to engage or interact with community members about their research and other related science topics. Of note, many of the researcher participants did not consider themselves to be experts in the two discussion topics. The prepared materials and agenda may have helped overcome time and confidence barriers, making participation inviting to researchers.

After participation in the Genome Diner program, researchers reported a marginally significant increase in their likelihood of participating in future public science activities $(P=0.05)$. Given the relatively high initial ratings $(M=6.7)$ and the large number of researchers who indicated they had participated in public engagement activities in the past, the researcher sample in this study likely had a preexisting interest in or commitment to public education. From the high level of satisfaction expressed by researcher participants, we speculate that the Genome Diner program affirmed their belief in the benefit of community engagement and strengthened their commitment to continued participation in public engagement. This, however, does suggest a self-selection bias and limits the generalizability of our findings.

Promoting researcher engagement with the public can be a challenge for several reasons, including the required time commitment, lack of experience, or failure to recognize the benefit of participating in such activities. Incentives to promote researcher participation could include the incorporation of Genome Diner into an activity that holds personal or professional interest. For example, departmental or faculty development programs, graduate school curricular activities, or linkages to a specific research study in which researchers are involved are all potential means of encouraging participation. In this way, programs like Genome Diner could help provide an enjoyable and mutually beneficial activity as well as strengthen ties between the institution and its community. 
The high level of education of many of the parent participants (almost double that reported for Durham, North Carolina, residents) indicates that there may have been self-selection bias in this population as well. We speculate that the higher education level may reflect a greater emphasis on education in general and thus a desire to participate in a program offered through their child's school. The higher education levels may have influenced researchers' beliefs about public knowledge, again limiting the generalizability of our findings. This also raises another challenge: that of recruiting members of the public who may not have a priori interest or may even have disinterest or lack of trust in genetics and research. We believe that the community partner is key to engaging a target audience. Genome Diner used the local school as a community center where diverse groups would feel comfortable and safe. Similar partners could include libraries, churches, and neighborhood centers.

Given the number of statistical tests performed, it is possible that we detected spurious findings. Because of the small sample size, we did not adjust for family-wise error rate using Bonferroni corrections (or other methods). The high number of significant findings detected in this low-power study, however, increases the likelihood that identified differences are genuine intervention effects. In addition, the fact that significantly positive changes were identified in a population that may have had more optimistic baseline perceptions may further demonstrate the impact of a program that brings researchers and the public to the same table.

As genetics and genomic research and clinical applications relevant to public health continue to expand, the success and translation of research and its findings will depend on the public's support and participation. The engagement format of the Genome Diner program presents a novel method of mutually promoting awareness of both the public and researchers. Researcher participants gained valuable, perspective-changing insight, particularly regarding public knowledge and attitudes about genome research and technology. Although focused on genomics, we believe the program format could work well with other science and health topics. Individuals wishing to implement Genome Diner or a similar program should consider the potential for recruiting challenges and develop strategic partnerships to address them. Further efforts are needed to explore ways to successfully sustain the immediately positive effects of participation.

\section{SUPPLEMENTARY MATERIAL}

Supplementary material is linked to the online version of the paper at http://www.nature.com/gim

\section{ACKNOWLEDGMENTS}

This work was supported by NIH R03HG005040. The award was through the NIH Partners in Research program.

\section{DISCLOSURE}

The authors declare no conflict of interest.

\section{REFERENCES}

1. Research!America. Taking Our Pulse: The PARADE/Research!America Health Poll. Charlton Research Company. Genetics and Personalized Medicine. 2004. http://www.researchamerica.org/uploads/ poll2004paradepersmed.pdf.

2. Ishiyama I, Nagai A, Muto K, et al. Relationship between public attitudes toward genomic studies related to medicine and their level of genomic literacy in Japan. Am J Med Genet A 2008;146A:1696-1706.

3. Catz DS, Green NS, Tobin JN, et al. Attitudes about genetics in underserved, culturally diverse populations. Community Genet 2005;8:161-172.

4. Sanderson SC, Wardle J, Jarvis MJ, Humphries SE. Public interest in genetic testing for susceptibility to heart disease and cancer: a population-based survey in the UK. Prev Med 2004;39:458-464.

5. Lanie AD, Jayaratne TE, Sheldon JP, et al. Exploring the public understanding of basic genetic concepts. J Genet Couns 2004;13:305-320.

6. Miller JD. Public Understanding of, and Attitudes toward, Scientific Research: What We Know and What We Need to Know. Public Underst of Sci 2004;13:273-294.

7. van der Sanden MCA, Meijman FJ. Dialogue guides awareness and understanding of science: an essay on different goals of dialogue leading to different science communication approaches. Public Underst of Sci 2008;17:89-103.

8. Wynne B. Public engagement as a means of restoring public trust in sciencehitting the notes, but missing the music? Community Genet 2006;9: 211-220.

9. Gottweis H. Gene therapy and the public: a matter of trust. Gene Ther 2002;9:667-669

10. Bates BR. Public culture and public understanding of genetics: a focus group study. Public Underst Sci 2005; 14:47-65.

11. Bates BR, Lynch JA, Bevan JL, Condit CM. Warranted concerns, warranted outlooks: a focus group study of public understandings of genetic research. Soc Sci Med 2005;60:331-344.

12. Cunningham-Burley S. Public knowledge and public trust. Community Genet 2006;9:204-210.

13. Brunk CG. Public knowledge, public trust: understanding the 'knowledge deficit.' Community Genet 2006;9:178-183.

14. Ferris D. Science Cafés tap nation's fascination with research and discoveries. Wired. 2007. http://www.wired.com/science/discoveries/news/2007/12/ science_cafe. Accessed 18 July 2011.

15. Goodman Research Group. NOVA scienceNOW Science Cafés Evaluation, 2007 $<$ http://sciencecafes.org/q_2007_study.pdf>.

16. New Economics Foundation. Democs. 2003. http://www. neweconomics org/projects/democs.

17. Duensing, Sally and Lorenzet, Andrea (2007). Decide Evaluation Report, March 2007, EC FP6 Decide Programme. <http://www. playdecide.org>. Accessed August 2008.

18. Play Decide. DEliberative CItizens DEbates. http://playdecide.eu.

19. NISE Network Public Forums Manual. Museum of Life and Science: Durham, NC, 2007.

20. Jallinoja P, Aro AR. Does knowledge make a difference? The association between knowledge about genes and attitudes toward gene tests. J Health Commun 2000;5:29-39.

21. Calsbeek H, Morren M, Bensing J, Rijken M. Knowledge and attitudes towards genetic testing: a two year follow-up study in patients with asthma, diabetes mellitus and cardiovascular disease. J Genet Couns 2007;16: 493-504.

22. City of Durham and Durham County NC. 2011 Community Indicator's Progress Report. Durham, NC, March 2011.

23. House of Lords Select Committee on Science and Technology. Science and Society, 3rd edn. HMSO: London, 2000. 